Archived version from NCDOCKS Institutional Repository http://libres.uncg.edu/ir/asu/

\title{
Appalachỉan
}

B O O N , NORTH CAROLIN A

\section{Depictions Of Female Protagonists In Digital Games: A Narrative Analysis Of 2013 DICE Award-Winning Digital Games}

\author{
By: Mildred F. Perreault, Gregory Pearson Perreault, Joy Jenkins, and Ariel Morrison
}

\begin{abstract}
Digital games historically hold a spotty record on gender depictions. The lack of depth in female characters has long been the norm; however, an increasing number of female protagonists are headlining games. This study used narrative theory to examine depictions of four female protagonists in four 2013 Design, Innovate, Communicate, Entertain Award-Winning Digital Games: The Last of Us, Bioshock Infinite, Tomb Raider, and Beyond: Two Souls. Studying these media depictions provides context for how women's stories are recorded in society. Stereotype subversions largely occur within familiar game narratives, and the female protagonists were still largely limited and defined by male figures in the games.
\end{abstract}

Perreault MF, Perreault GP, Jenkins J, Morrison A. Depictions of Female Protagonists in Digital Games: A Narrative Analysis of 2013 DICE Award-Winning Digital Games. Games and Culture. 2018;13(8):843-860. doi: $10.1177 / 1555412016679584$. Publisher version of record available at: https://journals.sagepub.com/doi/ full/10.1177/1555412016679584 
Games and Culture

\title{
Depictions of Female
} Protagonists in Digital Games: A Narrative 2018, Vol. I3(8) 843-860

(C) The Author(s) 2016 Article reuse guidelines: sagepub.com/journals-permissions DOl: $10.1177 / 15554 \mid 2016679584$ journals.sagepub.com/home/gac Analysis of 2013 DICE Award-Winning Digital Games

\section{Mildred F. Perreault', Gregory Pearson Perreault', Joy Jenkins ${ }^{2}$ and Ariel Morrison ${ }^{3}$}

\begin{abstract}
Digital games historically hold a spotty record on gender depictions. The lack of depth in female characters has long been the norm; however, an increasing number of female protagonists are headlining games. This study used narrative theory to examine depictions of four female protagonists in four 2013 Design, Innovate, Communicate, Entertain Award-Winning Digital Games: The Last of Us, Bioshock Infinite, Tomb Raider, and Beyond: Two Souls. Studying these media depictions provides context for how women's stories are recorded in society. Stereotype subversions largely occur within familiar game narratives, and the female protagonists were still largely limited and defined by male figures in the games.
\end{abstract}

\section{Keywords}

The Last of Us, Tomb Raider, Beyond: Two Souls, Bioshock Infinite, narrative theory, digital games, narrative, gender

\footnotetext{
' Appalachian State University, Boone, NC, USA

${ }^{2}$ Missouri School of Journalism, Columbia, Missouri, USA

${ }^{3}$ Independent Scholar

Corresponding Author:

Gregory Pearson Perreault, Appalachian State University, Boone, NC 28608, USA.

Email: perreaultgp@appstate.edu
} 
The 2013 video game Bioshock Infinite introduced the character Elizabeth, who was revered as a messianic figure throughout the game's narrative. Other denizens of the fictional floating city of Columbia referred to her at various times as a "savior" and as the "lamb." She could create "tears" through dimensions, yet this exceptional ability also cursed her. The leaders of Columbia imprisoned her, partially out of fear of her power. The imprisonment presented a stark contrast to the reverential discussion of Elizabeth within the city, encapsulated in a giant angel statue carved with her vestige.

Elizabeth's appearance evolved substantially during Bioshock Infinite. When the main character, private investigator Booker DeWitt, first met her, she wore the characteristic dress of 1912 small-town America, a long skirt and long-sleeved blouse, and her long hair was pulled back into a ponytail. She was not overly voluptuous, a notable difference from traditional game heroines (Jansz \& Martis, 2007), but her appearance suggested a femininity and innocence matching her savior/victim role. Eventually, however, Booker rescued Elizabeth, and she shed her former life of captivity and entered a dangerous world. This transition was symbolized through the destruction of the angel statue and Elizabeth donning more revealing clothing. Despite these jarring juxtapositions, the narrative surrounding Elizabeth — and, indeed, several other recent game heroines - suggested much more than a cut-and-dried presentation of oversexualized females.

A number of 2013 digital games featured female lead characters, characterized as more than objects to be obtained or rescued. The year 2013 was significant in gaming in that it represented the beginning of a technology transition-from Microsoft's Xbox 360 and Sony's Playstation 3 to the Xbox One and Playstation 4. During technology transitions, game designers often push the narrative limits of existing hardware as they forecast future capabilities in digital storytelling (Harris, 2014).

This study used narrative theory and the extant literature on gender and games as frameworks through which to examine depictions of four female protagonists in four 2013 Design, Innovate, Communicate, Entertain (DICE) Academy of Interactive Arts and Sciences Award Winners: Ellie in The Last of Us, Elizabeth from Bioshock Infinite, the redesigned Lara Croft in Tomb Raider, and Jodie in Beyond: Two Souls. This study found that the narratives constructed around female characters draw from previously established character tropes but, to a degree, also present deeper, more complex stories, effectively diversifying the traditional roles of women in digital games.

\section{Literature Review}

\section{Women in Game Narratives}

Women have been a part of gameplay, development, and participation and have been integral to gaming narratives since the creation of character games in the $1980 \mathrm{~s}$ (Cassell \& Jenkins, 1998). Even so, gaming culture is considered male-centric, and 
the gaming community has been characterized as "an unwelcoming space for women and other marginalized groups"' (Cote, 2015, p. 18).

These barriers are evident in character depictions, in that males tend to appear more frequently and more often drive the action in game narratives (Williams, Martins, Consalvo, \& Ivory, 2009). A content analysis of character representations in gaming magazines (Dill \& Thill, 2007) showed that male and female characters were typically portrayed in stereotypical ways, with female characters depicted as sexualized, scantily clad, and visions of beauty. Female characters often displayed "eroticized aggression," glamorizing both sex and aggression, which could limit their potential to serve as liberating figures (Dill \& Thill, 2007). In another study (Martins, Williams, Harrison, \& Ratan, 2009), female characters represented thinideal body types, with larger heads but smaller chests, waists, and hips than the average American woman.

That many games are designed for male players helps to explain the predominance of "stereotypical and sometimes demeaning representations of women" (King \& Kryzwinska, 2006, p. 183). However, it does not follow that players use the "signifiers of gender and appearance in the same way" (p. 184). An examination of 12 digital game players' social constructions of gender found evidence of both exaggerated masculinity (tough, strong, macho men) and sexualized femininity (objectification and misogyny; Delamere \& Shaw, 2008). Gamers recognized that the hypermasculine representation of men in the games does not necessarily reflect reality, despite the desirable social position it offered in gameplay (Delamere \& Shaw, 2008). However, while male players accepted hypersexualized female representations, female players largely criticized these depictions.

Problematic game depictions have also been shown to reinforce gender assumptions, such as hostile and benevolent sexism. Hostile sexism suggests that women seek to control men through sexuality, while benevolent sexism considers women as pure, weak, and in need of protection and support from men (Glick \& Fiske, 2001). Hostile sexism is more blatant than benevolent sexism, which seems positive, making it more difficult to recognize, although it promotes patronizing views of women (Barreto \& Ellemers, 2005). Benevolent sexism results in a "system of rewards and punishments that provide incentive for women to remain in conventional gender roles" (Glick \& Fiske, 2001, p. 116). Benevolent sexism can manifest in three key subfactors: protective paternalism (the need to rescue and provide for women), complementary gender differentiation (women as purer and more moral than men), and heterosexual intimacy (a man as incomplete without a woman to adore; Glick \& Fiske, 2001).

A recent content analysis examined the roles of female protagonists in digital games from 1983 to 2014 and assessed whether female characters were oversexualized (Lynch, Tompkins, van Driel, \& Fritz, 2016). Lynch, Tompkins, van Driel, and Fritz (2016) suggest that female characters portrayed as strong, capable, and attractive rather than oversexualized may draw more women to gaming. The current study evaluates gender narratives in recent games to provide a deeper understanding of and 
build upon the themes others have observed while also questioning whether these depictions have evolved.

\section{Gender and Gameplay}

The nature of gameplay differs between men and women. In a survey of men and women from fifth grade to college age, researchers found that, on average, gamers who reported to identify as men tended to play more each week than those who identified as women (Greenberg, Sherry, Lachlan, Lucas, \& Holmstrom, 2010). This difference may impact the production of award-winning games, in that big-budget games are likely to be geared toward an audience more likely to spend time playing them. Game publishers tend to be risk averse, resulting in games that reinforce the gender status quo (Johnson, 2013). Gaming behaviors differ by gender as well. In the study, men preferred action, shooting, and sports games, while women preferred classic board games and puzzle games (Greenberg et al., 2010). Both genders shared a secondary preference for adventure, fantasy, and strategy games.

Players may also subvert gender norms within gameplay and game narratives. For example, female gamers may play violent, aggressive, and otherwise unfeminine characters and games as well as continue gameplay in the face of criticism for gender nonconforming behavior (Delamere \& Shaw, 2008). In doing so, female gamers engage in "subversive appropriation of virtual bodies by 'real' gendered subjects" (Fantone, 2003, p. 58). Gender subversion within gameplay demonstrates the need to study not only the game experiences of those who identify as females but also the characters and narratives with which they interact.

Cassell and Jenkins (1998) trace the evolution of gender studies concerning games as well as the early patterns of female involvement in games' play, design, and participation. For example, the early gaming examples of the Blue Valkyrie from Gauntlet (1985) and Samus Aran of Metroid (1986) are often overlooked. Fighting games regularly feature a wide array of female characters; in particular, Street Fighter offers a wide variety of well-clothed and fearsome options for female play (Maccallum-Stewart, 2008). Chun Li became a fan-favorite option for arcade players of Street Fighter because she had the easiest skill set, yet was also the fastest character (Surman, 2007).

Ultimately, however, Kennedy (2002) argues that the experience of playing as a woman in games does not appear to have shaken the masculine nature of gaming culture. Kennedy suggests that "if we are going to encourage more girls into the gaming culture, then we need to encourage the production of a broader range of representations of femininity than those currently being offered" (para. 25). Developments in technology have made more representations possible. That is, more options for stories and narratives exist when games look like movies than when they consist of merely pixels on a screen. Hence, the player receives "greater freedom, within the constraints of its basic mechanism, including freedom to explore the on- 
screen world to some extent beyond the immediate requirements of advancement through the game" (King \& Kryzwinska, 2006, p. 3).

\section{Lara Croft and the Female Game Protagonist}

As games have developed, more female protagonists have appeared in game narratives (Lynch et al., 2016). In particular, Lara Croft of Tomb Raider has become central to many discussions of gender in gaming. Although games have continued to feature submissive, sweet, and oversexualized women (Jansz \& Martis, 2007), the development of characters like Lara Croft in the 1990s illustrates a transitory period for female game characters. Although the protagonist is sexualized in older versions of Tomb Raider, she is competent and dominant (Jansz \& Martis, 2007), rendering her a site of "gendered tension" in games (Maccallum-Stewart, 2008, p. 27).

Men tend to choose female avatars for narrative purposes, not because they identify with female gender (Maccallum-Stewart, 2008); however, the Tomb Raider games offer no alternative to Lara Croft. Lara Croft, like many females in the actionadventure media genre, was often sexualized in appearance (Grimes, 2003). The depiction of female characters often embodies masculine gender norms (Grimes, 2003). Hence, Lara Croft represents a site of digital transgendering in that a male player sees the abilities of a male body within alongside Croft's digitally elaborated feminine body. Therefore, the character exists as a mixture of both "object and willful subject" (King \& Krzywinska, 2006, p. 181).

Focusing on Lara Croft's appearance, clearly a site of male desire, may also neglect more nuanced assessments of the character (Maccallum-Stewart, 2008). That is, depictions of Lara Croft may be "demeaning, unrealistic, a site of horrific sexual deviance, a site of playful experimentation, bionic, sadistic and troublesome, but... also a heroine to women as well as to men" (Maccallum-Stewart, 2008, p. 32). Given the troubled history of Croft in games, many were intrigued when it was announced that the scriptwriter for the rebooted 2013 Tomb Raider game would be a woman, Rhianna Pratchett (Petitte, 2012, October 18). Yet, the emphasis on Lara Croft in research may suggest a lack of availability of other female avatars (Maccallum-Stewart, 2008), when other avatars are actually plentiful.

Addressing depictions of women in games involves a close examination of female characters and how players might "become" their characters in a game, in that a virtual reality may serve as a safe space for playful gender experimentation (Jansz, 2005; Jansz \& Martis, 2007). A level of interaction is required to prevent a character from taking a wrong turn or dying and for games featuring a prominent or dominant female character, players actively identify with a female character through this interaction (Grodal, 2003; Jansz \& Martis, 2007; Kiousis, 2002; Vorderer, 2000). Newer, stronger female characters deviate from the industry norm of dominant male protagonists. Studying how women are depicted in digital games, including the sexualization of female characters and the continued emphasis on 
submissiveness and timidity, can shed light on cultural conceptions of gender roles (Jansz \& Martis, 2007).

\section{Narrative Theory}

Digital game narratives play a role in shaping individual and cultural identities. Digital game narratives are dominated by character representations of male players; therefore, assessing female protagonists could help to illuminate how women's stories are recorded in society (Ivory, 2006). Narratives provide context for how future stories are understood and interpreted within culture (Foss, 1996) and can aptly contextualize stories, metaphors, and other literary elements (Carr, 1986; Fisher, 1995). "Identities are narratives" (Yuval-Davis, 2010), and the stories people tell and do not tell are narratives (Riessman, 2008, p. 8). Narrative pulls the imagined into the real world because "narrative is the proverbial ferry between the abstract and the concrete, between cognition and behavior, and between symbolic and the material" (Riessman, 2008, p. 16), helping the reader or viewer to make sense of lived experiences (Bold, 2011). The current study used narrative theory to identify themes, or mini-narratives, within larger texts.

Narrative analysis represents "a family of methods for interpreting texts that have in common a storied form" (Riessman, 2008, p. 11). Studies of narratives address two elements: narrative techniques and the laws that govern narrative structure (Bremond \& Cancalon, 1980). Laws reflect both the logical constraints a series of events must follow to be understood and additions to these constraints that fulfill the conventions of a particular culture; period; or, in this case, genre (Bremond \& Cancalon, 1980).

Bremond and Cancalon (1980) identify two types of narratives: "amelioration to obtain" and "degradation expected" (p. 392). Amelioration occurs when the hero faces an obstacle that "prevents the realization of a more satisfying state" (Bremond \& Cancalon, 1980, p. 392). Other characters, such as allies, play a role in addressing these obstacles and take different forms in relation to the hero, including interdependent associate, creditor, or debtor. When an amelioration process is complete, a new tension may emerge, resulting in degradation. In the degradation process, the narrator can be a beneficiary, if he commits an error with serious consequences, an aggressor, a creditor to whom the beneficiary is indebted, or a debtor in favor of whom the beneficiary sacrifices himself. Degradation can result from the hero fulfilling the request of an ally, sacrificing for an ally, submitting to aggression, error, or punishment. The reciprocity between a narrative's agent (the ameliorator or degrader) and patient (beneficiary or victim) is integral to the story's broader meaning (Bremond \& Cancalon, 1980). The current study considered each of these narrative elements, particularly the functions of female characters as agents, patients, and allies.

The researchers considered how four recent award-winning digital games narratively contextualized female characters. The games served as cultural artifacts, 
representing an American perspective as well as trends in American gaming culture. Therefore, two research questions informed the analysis:

Research Question 1: What roles did women play in these digital game narratives?

Research Question 2: What could these narratives reveal about the evolution of female depictions in American games?

To undertake the narrative research proposed here requires discussing specific plot devices. As such, the Findings section contains spoilers for the games.

\section{Method}

The researchers observed digital game "texts" and identified consistent themes throughout. Narrative thematic analysis involves sifting through long pieces of text (Riessman, 2008). However, definitions of a text extend beyond writing or language (p. 15). Interactive media such as digital games can also be considered texts (Aarseth, 1997).

The analysis focused on four 2013 DICE Academy of Interactive Arts and Sciences Award Winners, The Last of Us, Tomb Raider, Beyond: Two Souls, and Bioshock Infinite, focusing on their female protagonists. Of the four games, threeThe Last of Us, Tomb Raider, and Beyond: Two Souls - are considered adventure games, a secondary preference for both men and women (Greenberg et al., 2010). Bioshock Infinite is a first-person shooter, a genre that traditionally appeals to men (Greenberg et al., 2010).

After two researchers played the four games and identified preliminary themes, all four researchers watched the full-length digital game movies as presented via YouTube. They selected "play-throughs," which did not include narration. Although such games are "mediated," in that another player controls the avatar, the only audio presented is the audio from the game. Therefore, no external contextualization is provided. The play-throughs for The Last of Us, Tomb Raider, and Bioshock Infinite were recorded by YouTube user "dang08"; the play-through for Beyond: Two Souls was recorded by user "ComunityGame."

After the initial play-through and viewing of the gameplay movies, the researchers identified key themes emerging from the texts, which consisted of the entire games (Richardson \& St. Pierre, 2008). They then identified scenes in which the themes were particularly salient for deeper analysis. The researchers shared these scenes with one another in several research meetings in order to ensure consistency in the understanding of themes across games.

\section{Findings}

The researchers identified two dominant themes in the digital game narratives. In the first theme, all female protagonists possess a developed skill they use to progress 
through the game narrative and that complicates and enhances their relationships with dominant male characters. The second theme focuses on the female protagonist as a savior who is blessed as well as cursed. In this theme, the protagonist has (1) an inherent gift men want to capitalize on, (2) a desire to draw attention away from her sexuality, and (3) a lack of forced relationships (she is doomed to be alone because of her power).

\section{Theme I: The Developed Skill}

Beyond: Two Souls told the story of a young woman Jodie, played by actress Ellen Page. At the beginning of the game, Jodie's relationship with her invisible friend Aiden, who provided her with both nightmares and special abilities, was frustrating and occasionally traumatic. The 9-year-old girl was confused by what she sensed when Aiden took hold as well as when other dark spirits followed him. Early on, Jodie requested assistance from Aiden for minor tasks (to get a cookie out of the cookie jar, a box off the top of an armoire) and asked him to refrain from certain activities (picking up items that belong to her foster mother). Aiden protected her from bullies, and she could call on him for help when she faced other challenges. Jodie gained information from photos as well, which spurred flashbacks about her life and the lives of others.

However, as the game progressed, Aiden became angry when Jodie attempted to develop romantic relationships. In her first meeting with paranormal researcher Nathan Dawkins, Jodie stated, 'I don't tell Aiden what to do; no one does. He's like a lion in a cage. We're tied together. He can't go away. It's not my fault I want him to leave, too. He can be really scary sometimes" (Quantic Dream, 2013). In short, although Aiden was often helpful to her, Jodie felt no control over the relationship, and Aiden maintained the power.

Through Aiden, Jodie could see people who died, such as Dawkins' wife and daughter and later a homeless man's wife. Her ability to allow others to have conversations with the dead was just one way she harnessed her paranormal skills. She also used them to assist the Central Intelligence Agency (CIA) in killing a warlord in Somalia and, after the mission, fled as a traitor to the U.S. government. She befriended and saved a group of homeless people from a burning building and helped one of them give birth to a baby. She later befriended a family of Native Americans and saved them from a malevolent entity angered by their ancestors. Her ability to save and defend others grew as the character aged and developed confidence in her abilities. Yet in both of these cases, her success was dependent on Aiden.

The Last of Us featured Ellie, a young girl who was immune from a zombie disease that decimated humanity. However, Ellie's developed skill was her ability to fight beside Joel, a fellow survivor (and the game's protagonist) who had been tasked with taking Ellie to a group of scientists. The player played mainly as Joel and in short segments as Ellie-indicating that the development of Ellie's skill was 
vital to her playability as the story progressed. Further, Ellie developed her fighting skill despite Joel's adamant objections to giving her a gun or accepting her help. Yet, Joel clearly could not survive without Ellie. Their symbiotic relationship was also evident in the fact that Ellie appeared at various times wearing Joel's green jacket and his signature red flannel shirt. Her utility in both her time as a lead character and in her role as a support character may indicate narratively why Joel was unwilling to let her sacrifice herself in the final sequence of the game. In one scene, for example, Ellie learned to fire a gun and in doing so saved Joel's life, adding complexity to the protective, father-daughter relationship they developed.

Bioshock Infinite's Elizabeth displayed an array of unexpected skills. Her learned skills included picking locks and reading books. Elizabeth's ability to pick locks seemed to continually surprise Booker Dewitt, the game's protagonist, who, at one point, asked Elizabeth why she was so interested in this activity. She replied, "Being locked in a cage makes you want to learn such things" (Irrational Games, 2013). Elizabeth's captivity forced her to develop survival skills, and these skills played a pivotal role in propelling her and Dewitt through the game's narrative. Elizabeth adapted in other situations, continually leading Dewitt through various buildings and locales and, later in the game, tossing him ammunition as they encountered soldiers and other enemies, suggesting an evolution to more masculine abilities.

Elizabeth also displayed inherent skills that suggested traditionally feminine sensibilities, such as sensitivity, empathy, and goodness. Elizabeth continually served as a moral center during the game, questioning her and Dewitt's decisions and adding a level of complexity to the traditional blind-killing gameplay experience. For example, late in the game, after the two have murdered multiple people from Comstock's (Zachary Comstock, the villain in the game) army and the resistance, Elizabeth asked Dewitt, "Do you think it's possible to redeem the kinds of things that we've done?" and "Booker, are you afraid of God?" (Irrational Games, 2013). Booker, who is presented as having a precarious relationship with faith, replied, "No, but I'm afraid of you." Therefore, although the killings had already occurred, Elizabeth encouraged Dewitt to consider the implications of his actions not only personally but also spiritually.

Lara Croft's skills in Tomb Raider allowed her to navigate the island of Yamatai, searching for a way to save her friends and escape a cult. Lara had a number of mentors in her story but also followed in her explorer father's footsteps. Early in Lara's time on Yamatai, she encountered wolves and displayed her well-developed ability to conduct a counterattack with a bow and arrow (Crystal Dynamics, 2013). Lara was found by several of her friends, including Jonah, who said, "It's good to see you, little bird," to which she replied, "I'm so glad you're here. Is Sam with you?" (Crystal Dynamics, 2013). This scene juxtaposed Lara's independence and ability to care for and protect herself with her need for the group to provide a network of security to aid her in times of danger. This exchange also reinforced Lara's devotion to ensuring that her close friend, Sam, was well. Thus, Lara's acquired skills were complemented by her interest in ensuring her friends' wellbeing, suggesting both masculine and feminine characteristics. 


\section{Theme 2: The Cursed Savior}

Although the player of Bioshock Infinite experienced the game through the eyes of Booker Dewitt, Elizabeth played an equally important role. The game established early on that Dewitt was on a mission to rescue a girl, so he could alleviate himself of a debt. As he journeyed to find the girl, Dewitt saw indications of her role. In the early stages of the game, she was called a "miracle child," "the lamb," and "the future of our community" (Irrational Games, 2013). This use of religious language implied a character that transcended human qualities to take a savior-like role. In contrast, Zachary Comstock, referred to Dewitt as a "false prophet coming to lead his lamb astray" (Irrational Games, 2013). Although the player may have viewed Dewitt as the game's hero, he was portrayed as a potential foil to the saintly Elizabeth. At other points in the game, Dewitt served as Elizabeth's protector and, ultimately, as her father.

Elizabeth's role as a savior was evident in a variety of otherworldly abilities she displayed in the game. These powers included bringing the dead to life and creating tears or portals to other worlds. Some of these worlds were alternate versions of reality, while others depicted past events. Elizabeth told Dewitt that her connection with the tears had been evident since childhood, when she could create tears to anywhere she wanted to go. Elizabeth realized her gifts differentiated her from others in society, which was initially scary and confusing, although she eventually recognized the importance of these qualities to protecting humanity.

During the game, Elizabeth evolved from an innocent captive to a sage spiritual guide who helped Dewitt come to terms with his past - a transition that was evident in her exchange of a demure, long-sleeved blouse for a cleavage-bearing bustier. Throughout these experiences, Elizabeth maintained a moral perspective that led her to question acts she saw as wrong, namely, murder. Although Dewitt justified the need for these actions, Elizabeth suggested this wrongdoing could negatively affect their favor with God. Although Dewitt resisted these questions, Elizabeth helped him discern his spirituality as well as his true identity.

Lara Croft's interest in religious relics took her on a journey across a remote island, where her quest and ability to save herself and her friends from capture reflects a narrative of a female savior. In one scene in Tomb Raider, she saved her friend from a group of raiders on the island who kidnapped and tortured her. Although Croft's abilities were more practical and physical than innate and otherworldly, she exhibited an undying loyalty to those she cared for through those actions, seemingly blending masculine and feminine sensibilities.

In The Last of Us, Ellie's inherent gift was her immunity from the zombie disease. Joel wore a face mask when he ventured too close to the disease spores, but Ellie, his surrogate daughter, did not. This ability clearly demarcated Ellie from the other characters during gameplay. Although much of human society died off from the invasive zombie fungus, Ellie survived a zombie bite and walked through fungusinfested areas unprotected. Ellie's immunity to the disease immediately granted her 
value among any group that discovered her nature. In particular, Marlene, one leader of the Fireflies - a rebel prodemocracy group - saw Ellie as the cure for the disease and the beginning of a path to reinstituting American democracy.

Simultaneously, this gift was a curse. As Ellie argued in confronting Joel, "Everyone I have known has either left me or died ... everyone fucking except for you" (Naughty Dog, 2013). Throughout the game, players witnessed the implications of Ellie's gift: First, her friend Riley died, and then Joel's partner, Tess, sacrificed herself to save Ellie, and Joel had a near brush with death trying to get Ellie to the Fireflies. Even on the level of gameplay, the act of getting Ellie to the Fireflies required that she and Joel kill fellow survivors throughout the game.

In the climactic final episode of the game, Joel and Ellie reached the Fireflies. There, Joel was told that because the zombie fungus grows in the brainstem, Ellie's brain needed to be removed to reverse engineer a cure. Although Ellie's inherent gift gave her the potential to save humanity, Joel prevented her from fulfilling this role. Unable to give up Ellie, he spent the last episode of the game killing the Firefliesimplied to be the hope of humanity - in order to save her.

This narrative demonstrated how a powerful male figure worked to lessen both Ellie's saving power and her curse. Ellie's curse was that she was alone and constantly hunted. Joel served as her protector and constant companion. Yet, it is clear that Ellie was willing to give her life to see the disease end. Joel prevented her from doing what she needed to do to save the world. So, in short, Joel diminished the two aspects of Ellie that made her unique. By staying with her and refusing to let her "die for the cause," he lessened her separation from the rest of humanity. However, he also prevented her from using her gift to help others, which deprived her of the opportunity to choose how she should use her power as well as whether she should live or die.

In Beyond: Two Souls, the benefits of Jodie's connection to Aiden were initially unclear. From the beginning of the game, people referred to Jodie as "disturbed," "odd," and "a brave little girl" (Quantic Dream, 2013). Other children and her foster parents feared her because they did not understand her abilities. When Jodie lived at the government's paranormal research facility, researchers Cole Freeman and Nathan Dawkins watched her through cameras in her bedroom, almost like an animal in a cage, so they could "figure out what's going on" (Quantic Dream, 2013). This surveillance allowed them to help her when the evil, nightmarish spirits attacked her.

As a young adult, Jodie became insecure and rebellious. This behavior changed, however, when she was asked to help close a "rift" opened by the government at a research facility. Dawkins took Jodie to the facility in the middle of the night, stating, "I told them you were just a child, but they know only you know how to deal with what lies beyond the rift" (Quantic Dream, 2013). She managed to close the rift, thanks to Aiden sending the bad "entities" back to their dimension. Dawkins gave her the option to refuse, but she willingly took on the task. This was just one of the many scenes in the game where Jodie demonstrated otherworldly abilities and 
sacrificed her well-being to help others while also displaying increasing agency in choosing how to respond to challenging situations.

\section{Discussion}

This evaluation of digital game narratives featuring female protagonists suggests that these games are pushing boundaries and redefining where women fit within digital stories. Traditional views of female identity are manipulated and reassigned, but within traditionally accepted frames.

In these games, the dominant female characters possess a blend of inherent and learned skills. All of these qualities serve important roles, both for the game-playing experience and the games' narratives.

Bioshock Infinite's Elizabeth was not only a skilled lock picker who provided protagonist Booker Dewitt with ammunition, but she also had otherworldly abilities, including the power to bring the dead back to life and travel through tears into alternate worlds. Eventually, this ability allowed her and Dewitt to escape their pursuers while revealing Dewitt's ultimate fate and positioning Elizabeth as potentially the game's most powerful character.

Similarly, Jodie, the protagonist of Beyond: Two Souls, was linked to Aiden. Like Elizabeth, she felt ostracized because of Aiden and, as a result, learned skills and coping mechanisms that helped her to survive in a world that didn't understand her. Ellie, of The Last of Us, too, had marksmanship and resourcefulness that helped Joel traverse a world full of zombies. Ellie was the youngest of the female lead characters in this study, but she learned skills that helped her take on a role beyond mere cargo.

These female characters represented a shift in digital games overall, a medium that has tended to emphasize stereotypical representations of women as submissive, sweet, and sexualized (Delamere \& Shaw, 2008; Jansz \& Martis, 2007; King \& Kryzwinska, 2006; Sampaio \& Aragon, 2001). Rather than proverbial princesses in need of rescue, these characters evolved into self-sufficient, confident women who contributed not only to their own survival but also the survival of male characters.

This change may be, in part, necessitated by the fact that players have to play as a female character in three of the games examined. In Tomb Raider and Beyond: Two Souls, in particular, the player has no male option. Because male gamers continue to spend more time playing than female ones (Greenberg et al., 2010), game publishers would be unlikely to present a weak female lead character, particularly when a capable, strong, and emotionally complex avatar contributes to a far more interesting narrative (Maccallum-Stewart, 2008). While The Last of Us and Bioshock Infinite did not primarily allow the player to control the female character-Ellie was played primarily for a short portion of the game and Elizabeth not at all — the player was able to direct how they assisted you. For example, Ellie could be asked to help Joel progress, for example, by getting ladders and boxes to climb on, and Elizabeth could be directed to open tears that could help the player during the combat. 
However, although each of these characters displayed qualities or abilities that were unquestioningly powerful-typically more powerful than the abilities shown by the male primary characters - the gifts tended to manifest in traditionally feminine ways. For example, women are generally considered to possess a natural ability to serve as caregiver or nurturer, situating them within the traditional motherhood role. This ability is not seen as developed or learned but innate to a woman's consciousness. Elizabeth and Jodie were unsure of the depths or limits of their abilities and were even afraid of them. These skills, thus, resulted in both women feeling as if they did not truly belong in the world. Ellie felt similar isolation as a result of her immunity, a quality she did not ask for but that came to define her. Thus, these characters not only represented savior figures, but they were also cursed by their otherness.

Depicting female characters as pure, weak, and in need of protection suggests a presence of benevolent sexism, particularly in the complementary gender roles in the games. Characters displayed characteristics that, on the surface, seemed positive and advantageous, but these qualities actually reinforced problematic views of women as lacking (Barreto \& Ellemers, 2005). Although these gifts enhanced gameplay and contributed to the narrative development of the female characters, they also reified conventional gender roles, such as women as purer and more moral than men and men as incomplete without a woman to adore. Therefore, the gifts may be rendered as more of a curse than a blessing.

Additionally, the female characters in the games not only adapted to their surroundings, with help from their male counterparts, and took on new, more masculine skills, but they also used their feminine abilities as strengths. They showed sensitivity and intuition in challenging situations, when the male character may have been prone to a violent response. For example, Elizabeth, when confronting Songbird, the giant robot that served as her keeper prior to her rescue, did not resort to destroying him outright but gently calmed him, easing him to his fate. This interaction was markedly different from other, more violent sequences in the game. This characteristically female trait was reconstituted as strength by subverting an expected (masculine) response. Similarly, although Lara Croft was depicted as powerful and intelligent, she was also compassionate and kind, blending stereotypically masculine and feminine characteristics to create a character that reinforces a sense of gendered tension (Maccallum-Stewart, 2008).

Female characters were also treated as cursed in a manner that revealed their normalcy and capacity for making mistakes. A close examination of characters like Elizabeth and Lara revealed that while these women were placed in a unique role as savior, the traits that contributed to this messianic position also supported the humanity of these characters. For example, Lara's skills and abilities in Tomb Raider were impeccable but not without flaws. Lara's dependence on her friends for help and survival displayed how she and other female leads were not autonomous. The significance of the submissive traits of females in early games may influence the occasional humility of female characters in contemporary games. Rather than 
emphasize female characters as submissive and voiceless, the games should layer their personalities with aspects of humanity and community, adding a vital dose of complexity that will carry games - and female depictions - forward.

Through repetitive actions in gameplay mechanics, the female characters negotiated their identity and defined their importance to the narrative. In Bioshock Infinite, Elizabeth gathered ammunition for Booker, unlocked doors, and opened dimensional portals to provide support for Booker during battle. In The Last of $U s$, Ellie provided covering fire for Joel throughout much of the gameplay. In both of these cases, the female characters' developed skills showed their salience to the game, not just as an element of the plot but also an integral part of gameplay. In Tomb Raider, Lara Croft had to build fires to save her progress, customize her weapons, and learn new skills. In gameplay terms, building fires served the opposite purpose one would expect in that fires played a preservational role. This repetitive action reminded players of how far Lara had progressed, and how far she still had to go through the presentation of a "completion percentage" (Crystal Dynamics, 2013).

These depictions subverted traditional narrative structures, with characters, specifically Elizabeth and Ellie, becoming less dependent on male protagonists through invoking their inherent and learned skills, transitioning them from allies or patients into narrators and affording them enhanced roles in both the amelioration and degradation processes (Bremond \& Cancalon, 1980). These shifts may have provided opportunities for gender experimentation among both male and female gamers who became engaged with these characters throughout gameplay (Jansz, 2005; Jansz \& Maratis, 2007).

In contrast, in Beyond: Two Souls, Jodie's repetitive action occurred through controlling Aiden, who allowed her to control minds, move objects, and knock out threats. In order to progress through the game, Jodie engaged Aiden both verbally and mentally to obtain his help in accomplishing tasks. Observed in abstraction, what occurred between Jodie and Aiden is the mirror gender image of what happened between Elizabeth and Booker. Whereas Elizabeth helped Booker, which allowed the plot to progress, Aiden helped Jodie. Therefore, Jodie was indebted to Aiden, which shaped her narrative, although their relationship provided opportunities to consider the narrative reciprocity between the two (Bremond \& Cancalon, 1980). Repetitive actions were less emphasized in Tomb Raider and even less so in Beyond: Two Souls. But in both cases, the player controlled the female character for much of the game.

These repetitive actions served to progress the narratives and assert the importance of the female characters in the games studied. Even so, these actions, particularly in The Last of Us and Bioshock Infinite, limited female characters' agency. By supporting male characters with their actions, the female characters at once asserted their importance to the gameplay while also fulfilling "safe" roles from a cultural context. At the same time, one could argue that change occurs incrementally, so these repetitive actions benefited female characters rather than relegating them to cargo. 
Although promising elements emerged from this study - in particular, in Beyond: Two Souls and The Last of Us - troubling components of traditional female depictions remain. The most promising element of the games studied is that the women were all integral to the games' narratives - and, in fact, can change the direction of the stories. There is subtle evidence that depictions of women may be shifting in that the women were presented as capable, confident, and multifaceted. This trend could reflect a shift in the audience to which the games are geared, as more and more women have begun playing games - particularly, the adventure games dominant in this sample. Yet, the women in these narratives were still heavily reliant on male figures.

It is worth noting that among Game of the Year award nominees after the technological transition - in 2014 and 2015 in particular - the emphasis on male protagonists returned. In 2014, only a single game placed players into the role of a female protagonist, Bayonetta 2, and the game received backlash about the main character's oversexualization (Greenwald, 2014). Other 2014 Game of the Year award nominees forced players to play as male protagonists, or, in the case of Dragon Age: Inquisition, allowed them to choose their gender. Similarly, in 2015 award nominees, Fallout 4 allowed players to pick a gender, but none of the other games offered an option for a leading female character. So 2013, as a digital transition year, showed that game developers pushed boundaries, if only slightly, yet the top games of that year did not seem to usher in lasting change in game narratives.

\section{Conclusion}

Overall, the prominence of intriguing female protagonists in four popular digital games from 2013 offered an opportunity for players to engage in an "appropriation of virtual bodies"' (Fantone, 2003, p. 58) in unexpected ways. These characters were not merely sidekicks or rescuees; they played important roles in the gameplay experiences and narratives associated with the games, presenting themselves as female saviors with powerful inherent and learned skills. These characters challenged the female stereotypes that have been pervasive in digital games, such as sexualization and eroticized aggression (Dill \& Thill, 2007). These shifts were subtle - as remnants of previous approaches to female depiction remain evident - but they offered an opportunity for gamers, both male and female, to immerse themselves in narratives featuring complex, multifaceted female heroines.

Although three of the games examined reflected the action-adventure genre-which is a secondary preference for men and women-men overall have more enthusiasm for games, and this is true for the adventure genre as well. The other game-Bioshock Infinite-was created in a genre geared explicitly for men. Although this fact does not change the nature of the depictions noted, it does perhaps raise questions about the audience. It could be that the "gamer" audience continues to be conceived of as solely male (Cote, 2015). Future research should explore expressions of gender in the puzzle and traditional board game genres in that this is a type of play that is more preferred by female game players (Greenberg et al., 2010). 


\section{Acknowledgment}

The authors would like to acknowledge the Missouri School of Journalism for allowing us great research freedom and the editors of Games \& Culture for their time and effort.

\section{Declaration of Conflicting Interests}

The author(s) declared no potential conflicts of interest with respect to the research, authorship, and/or publication of this article.

\section{Funding}

The author(s) received no financial support for the research, authorship, and/or publication of this article.

\section{References}

Aarseth, E. J. (1997). Cybertext: Perspectives on ergodic literature. Baltimore, MD: Johns Hopkins University Press.

Barreto, M., \& Ellemers, N. (2005). The burden of benevolent sexism: How it contributes to the maintenance of gender inequalities. European Journal of Social Psychology, 35, 633-642.

Bold, C. (2011). Using narrative in research. Thousand Oaks, CA: Sage.

Bremond, C., \& Cancalon, E. D. (1980). The logic of narrative possibilities. New Literary History, 11, 387-411.

Carr, D. (1986). Time, narrative, and history. Bloomington: Indiana University Press.

Cassell, J., \& Jenkins, H. (1998). From Barbie to Mortal Kombat: Gender and computer games. Cambridge, MA: MIT Press.

Cote, A. C. (2015). Writing "Gamers" the gendered construction of gamer identity in Nintendo power (1994-1999). Games and Culture. doi:10.1177/1555412015624742

Crystal Dynamics. (2013). Tomb Raider [Xbox 360/Playstation 3/PC game]. Redwood City, CA: Square Enix.

Delamere, F. M., \& Shaw, S. M. (2008). “They see it as a guy's game”: The politics of gender in digital games. Leisure/Loisir, 32, 279-302.

Dill, K. E., \& Thill, K. P. (2007). Video game characters and the socialization of gender roles: Young people's perceptions mirror sexist media depictions. Sex Roles, 57, 851-864.

Fantone, L. (2003). Final fantasies virtual women's bodies. Feminist Theory, 4, 51-72.

Fischer, H. W., Schaeffer, S., \& Trowbridge, M. L. (1992). The impact of media blame assignation on the EOC response to disaster: A case study of the response to the April 26, 1991, Andover (Kansas) Tornado. Quick Response (Report \#48). Boulder, CO: University of Colorado, Natural Hazards Research and Applications Information Center.

Fisher, W. R. (1995). Narration, knowledge, and the possibility of wisdom. In W. R. Fisher \& F. Goodman (Eds.), Rethinking knowledge: Reflections across the disciplines (169-192). New York: State University of New York Press.

Foss, S. K. (1996). Rhetorical criticism: Exploration and practice. Prospect Heights, IL: Waveland Press. 
“Game Player Data." (2013). Entertainment Software Association. Retrieved February 26, 2014, from http://www.theesa.com/facts/gameplayer.asp

Glick, P., \& Fiske, S. T. (2001). An ambivalent alliance: Hostile and benevolent sexism as complementary justifications for gender inequality. American Psychologist, 56, 109.

Greenberg, B., Sherry, J., Lachlan, K., Lucas, K., \& Holmstrom, A. (2010). Orientations to video games among gender and age groups. Simulation \& Gaming, 41, 238-259.

Greenwald, W. (2014, October 14). Bayonetta is sexy, strong, and not scandalous. PC Magazine. Retrieved from http://www.pcmag.com/article2/0,2817,2470362,00.asp

Grimes, S. M. (2003, November). "Shoot Like A Girl!": The female protagonist in actionadventure video games. Proceedings of the 2003 Digital Games Research Association International Conference: Level Up, Utrecht, the Netherlands.

Grodal, T. (2003). Stories for eye, ear, and muscles: Video games, media, and embodied experiences. In M. J. P. Wolf \& B. Perron, The video game theory reader (pp. 129-155). London, England: Routledge.

Harris, B. (2014). Console wars: Sega, nintendo, and the battle that defined a generation. New York, NY: Dey Street Books.

Irrational Games. (2013). Bioshock Infinite [Xbox 360/Playstation 3/PC game]. Boston, MA: $2 \mathrm{~K}$ Games.

Ivory, J. D. (2006). Still a man's game: Gender representation in online reviews of video games. Mass Communication \& Society, 9, 103-114.

Jansz, J. (2005). The emotional appeal of violent video games for adolescent males. Communication Theory, 15, 219-241.

Jansz, J., \& Martis, R. G. (2007). The Lara phenomenon: Powerful female characters in video games. Sex Roles, 56, 141-148.

Johnson, R. (2013). Toward greater production diversity: Examining social boundaries at a video game studio. Games \& Culture, 8, 136-160.

Kennedy, H. W. (2002). Lara Croft: Feminist icon or cyberbimbo? On the limits of textual analysis. Game Studies: International Journal of Computer Games Research, 2.

King, G., \& Krzywinska, T. (2006). Tomb raiders and space invaders: Forms and meanings of videogames. London, England: IB Tauris.

Kiousis, S. (2002). Interactivity: A concept explication. New Media and Society, 4, 355-383.

Lynch, T., Tompkins, J. E., van Driel, I. I., \& Fritz, N. (2016). Sexy, strong, and secondary: A content analysis of female characters in video games across 31 Years. Journal of Communication, 66, 564-584.

Maccallum-Stewart, E. (2008). Real boys carry girly epics: Normalising gender bending in online games. Eludamos: Journal for Computer Game Culture, 2, 27-40.

Martins, N., Williams, D. C., Harrison, K., \& Ratan, R. A. (2009). A content analysis of female body imagery in video games. Sex Roles, 61, 824-836.

Naughty Dog. (2013). The Last of Us [Playstation 3 game]. Santa Monica, CA: Sony Computer Entertainment.

Perreault, G. (2013). Text, image, violent games and god: A concept explication of depiction. Paper presented at the International Communication Association, London, England. 
Petitte, O. (2012, October 18). Tomb Raider lead writer sees "no reason" to avoid sensitive storytelling themes in games. PC Gamer. Retrieved from http:/www.pcgamer.com/tombraider-writer-sensitive-storytelling-themes/

Quantic Dream. (2013). Beyond: Two souls [Playstation 3 game]. Paris, France: Sony Computer Entertainment.

Richardson, L., \& St Pierre, E. A. (2008). A method of inquiry. Collecting and Interpreting Qualitative Materials, 3, 473.

Riessman, C. K. (2008). Narrative methods for the human sciences. Thousand Oaks, CA: Sage.

Sampaio, A., \& Aragon, J. (2001). Filtered feminisms: Cybersex, e-commerce, and the construction of women's bodies in cyberspace. Women's Studies Quarterly, 29, 126-147.

Surman, D. (2007). Pleasure, spectacle and reward in streetfighter II. In B. Atkins \& T. Kryzwinska (Eds.), Videogame, player, text (pp. 204-221). Manchester, England: Manchester University Press.

Vorderer, P. (2000). Interactive entertainment and beyond. In D. Zillmann \& P. Vorderer (Eds.), Media entertainment (pp. 21-37). Mahwah, NJ: Erlbaum.

Williams, D., Martins, N., Consalvo, M., \& Ivory, J. D. (2009). The virtual census: Representations of gender, race and age in video games. New Media \& Society, 11, 815-834.

Yuval-Davis, N. (2010). Theorizing identity: Beyond the 'us' and 'them' dichotomy. Patterns of Prejudice, 44, 261-280.

\section{Author Biographies}

Mildred F. Perreault applies narrative theory to research on the role of media in disaster preparedness and postdisaster recovery. Her research examines the roles of media producers in changing culture through media.

Gregory Pearson Perreault is a media sociologist who studies the role of media paradigms in the portrayal of minorities. His work has been published in Journalism: Theory, Criticism and Practice, Howard Journal of Communication, and Journal of Media \& Religion.

Joy Jenkins uses critical-cultural and feminist theoretical lenses to examine the changing roles of editors within newsrooms and the potential for local media to spur social change.

Ariel Morrison studies depictions of women, health, and sexuality. She collaborated with Dr. Gregory Perreault for an academic journal article on media and religion and is currently focused on the intersection of media, religion, and public health. 